\title{
A Design Comparison of Atmospheric Flight Vehicles for the Exploration of Titan
}

\author{
Joseph F. Gasbarre ${ }^{*}$ and Henry S. Wright ${ }^{\dagger}$ \\ NASA Langley Research Center, Hampton, VA, 23666 \\ Mark J. Lewis ${ }^{\ddagger}$ \\ University of Maryland, College Park, MD, 20410
}

\begin{abstract}
Titan, the largest moon of Saturn, is one of the most scientifically interesting locations in the Solar System. With a very cold atmosphere that is five times as dense as Earth's, and one and a half times the surface pressure, it also provides one of the most aeronautically fascinating environments known to humankind. While this may seem the ideal place to attempt atmospheric flight, many challenges await any vehicle attempting to navigate through it. In addition to these physical challenges, any scientific exploration mission to Titan will most likely have several operational constraints. One difficult constraint is the desire for a global survey of the planet and thus, a long duration flight within the atmosphere. Since many of the scientific measurements that would be unique to a vehicle flying through the atmosphere (as opposed to an orbiting spacecraft) desire near-surface positioning of their associated instruments, the vehicle must also be able to fly within the first scale height of the atmosphere. Another difficult constraint is that interaction with the surface, whether by landing or dropped probe, is also highly desirable from a scientific perspective. Two common atmospheric flight platforms that might be used for this mission are the airplane and airship. Under the assumption of a mission architecture that would involve an orbiting relay spacecraft delivered via aerocapture and an atmospheric flight vehicle delivered via direct entry, designs were developed for both platforms that are unique to Titan. Consequently, after a viable design was achieved for each platform, their advantages and disadvantages were compared. This comparison included such factors as deployment risk, surface interaction capability, mass, and design heritage. When considering all factors, the preferred candidate platform for a global survey of Titan is an airship.
\end{abstract}

\section{Nomenclature}

$\rho \quad=$ density

$m \quad=$ mass

$g \quad=$ gravity

$C_{L} \quad=$ three-dimensional lift coefficient

Re $\quad=$ Reynolds number

$V \quad=$ flight velocity or volume (airship)

$n \quad=$ propulsive efficiency parameter

$\eta \quad=$ efficiency factor

$P \quad=$ power

$c g \quad=$ center of gravity

$L \quad=$ lift

$C B E=$ current best estimate

$M E \quad=$ max expected

\footnotetext{
* Aerospace Engineer, Structural and Thermal Systems Branch, M/S 431, AIAA Member.

${ }^{\dagger}$ Aerospace Engineer, Exploration Systems Engineering Branch, M/S 143, AIAA Member.

₹ Professor, Department of Aerospace Engineering, 3188 Martin Hall, AIAA Fellow.
} 


\section{Introduction}

$\mathrm{T}$ itan, the largest moon of the planet Saturn, has long held great interest among the scientific community, but with the advent of the NASA/ESA Cassini/Huygens mission, interest is sure to be renewed and amplified. With this interest naturally comes the desire to follow the Huygens Probe's discoveries with another, more comprehensive Titan mission, similar to how Mars missions have grown in scale since the first probes arrived decades ago. Unlike Mars, a dedicated mission to Titan is estimated to be costly due to the excessive expenditure of energy necessary to deliver a meaningful system to Titan from Earth. With this in mind, NASA commissioned several studies to explore "Flagship"-type missions (mission cost $>\$ 700 \mathrm{M}$ ) to the outer planets, including Titan. The work presented in this paper is a small part of one of those studies which focused on exploring Titan with an aerial vehicle platform (Titan Explorer). The relatively thick atmosphere and low gravity on Titan compared to that of Earth appear to provide the perfect environment for the use of an aerial platform for the investigation of Titan, and as such, has spurred many previous aerial vehicle design studies. In this case, it was necessary to provide NASA with insight into what these aerial platforms might look like, their advantages and disadvantages, and which of the candidate platforms might be preferable based on a realistic mission scenario. Thus, the common theme throughout this study was to base the preliminary designs, as well as the comparisons of those designs, on a realistic set of possible science requirements and an actual, detailed mission architecture that has been developed to accommodate the exploration of Titan in the 2025 timeframe.

\section{Titan Background and Study Assumptions}

\section{A. Science Rationale}

One of the fundamental questions in all of science concerns the origin and evolution of life and the occurrence of life in the Solar System. In the search for life outside the Earth, Titan, the largest moon of Saturn, holds a very unique position. Titan (radius of $2575 \mathrm{~km}$ ) is slightly larger than Mercury (radius of $2439 \mathrm{~km}$ ) and smaller than Mars (radius of $3393 \mathrm{~km}$ ). Like the terrestrial planets, Titan has a solid surface and a density that suggests it is composed of a mixture of rock and ice in almost equal amounts. Titan may provide the details to explain how life formed on Earth very early in its history, shortly after the Earth formed 4.6 billion years ago. The evolution of the Earth's atmosphere and plate tectonics have erased any early record of the primitive pre-biological Earth (the Earth's geological record begins with the oldest rocks on our planet, dated to be about 3.5 billion years old, about a billion years after the Earth formed). The appearance on Earth of the first biological or living system and the subsequent evolution of biological systems, were preceded by the process of prebiotic chemistry or "chemical evolution." Chemical evolution is the formation of the complex organic compounds, the precursors of living system. It is generally believed, that on Earth, chemical evolution occurred very soon after the Earth and its atmosphere formed. It is further believed that the gases in the early atmosphere, including nitrogen, methane, water vapor, molecular hydrogen, etc. were the "raw" materials that chemically formed the complex organic molecules, the precursors for the first living system.

A set of key scientific themes have been developed to provide context for a mission assessment which has in-situ investigations as a key component. Investigation of the atmosphere of Titan, understanding the meteorology and circulation of the atmosphere of Titan, and characterizing the nature of the surface of Titan form the essential scientific themes upon which the mission assessment was based.

\section{Atmosphere of Titan}

Titan's atmosphere may hold answers to chemical evolution on the early Earth ${ }^{1-3}$. Titan is surrounded by a thick, opaque orange-colored atmosphere with a surface pressure of 1.5 bars-about $50 \%$ greater than the Earth's atmosphere. Similar to the Earth, molecular nitrogen $\left(\mathrm{N}_{2}\right)$ is the overwhelming constituent of the Titan atmosphere (about $95 \%$ by volume), with smaller amounts of methane $\left(\mathrm{CH}_{4}\right)$ and molecular hydrogen $\left(\mathrm{H}_{2}\right)^{4}$. The stability of methane in Titan's atmosphere is puzzling, since the atmospheric lifetime of methane is controlled by its destruction by solar ultraviolet radiation, which is short on cosmic timescales ( $10^{7}$ years). Hence, atmospheric methane on Titan appears to be buffered or re-supplied by a possible surface reservoir. The cloud and haze are sufficiently thick that ultraviolet radiation cannot penetrate to the troposphere. Photochemical and chemical reactions initiated by methane (and nitrogen) leads to the production of numerous hydrocarbons of increasing molecular complexity, beginning with ethane, hydrogen cyanide, etc., and leading to complex organic compounds such as purines, pyrimidines, and aldehydes, believed to be the chemical precursors of the first living systems on Earth ${ }^{1-3}$. The constituents of Titan's atmosphere ${ }^{4}$ are given in Table 1. The dominance of nitrogen on Titan gives rise to the rich coupled chemistry between nitrogen and carbon. The variety of nitrile species on Titan appears to be unique in the Solar System. As already noted, it is generally believed that the atmosphere of Titan is very similar to the Earth's primordial, pre- 
biological atmosphere, the atmosphere that produced the complex organic molecules that led to the formation of living systems on Earth in its early history.

The early history and evolution of the atmosphere of Titan is a key scientific question. Due to its low gravitational attraction $\left(g=135 \mathrm{~cm} / \mathrm{sec}^{2}\right)$, Titan can easily lose atomic $(\mathrm{H})$ and molecular $\left(\mathrm{H}_{2}\right)$ hydrogen to space. With the loss of hydrogen (both atomic and molecular), the

Table 1. Primary Atmospheric Constituents on Titan

\begin{tabular}{|l|l|l|l|}
\hline Component & Symbol & Component & Symbol \\
\hline Nitrogen & $\mathrm{N}_{2}$ & Hydrogen Cyanide & $\mathrm{HCN}$ \\
\hline Methane & $\mathrm{CH}_{4}$ & Acetylene & $\mathrm{C}_{2} \mathrm{~N}_{2}$ \\
\hline Molecular Hydrogen & $\mathrm{H}_{2}$ & Butane & $\mathrm{C}_{4} \mathrm{H}_{10}$ \\
\hline Ethane & $\mathrm{C}_{2} \mathrm{H}_{6}$ & Carbon Monoxide & $\mathrm{CO}$ \\
\hline Ethylene & $\mathrm{C}_{2} \mathrm{H}_{4}$ & Water Vapor & $\mathrm{H}_{2} \mathrm{O}$ \\
\hline Propane & $\mathrm{C}_{3} \mathrm{H}_{8}$ & Formaldehyde & $\mathrm{H}_{2} \mathrm{CO}$ \\
\hline Methyl Acetone & $\mathrm{CH}_{3} \mathrm{C}_{2} \mathrm{H}$ & Methyl Cyanide & $\mathrm{CH}_{3} \mathrm{CN}$ \\
\hline Diacetylene & $\mathrm{C}_{4} \mathrm{H}_{2}$ & Acetaldehyde & $\mathrm{CH}_{3} \mathrm{CHO}$ \\
\hline
\end{tabular}
production of complex hydrocarbons becomes irreversible. For example, $96 \%$ of the dissociation of methane results in the production of complex hydrocarbons on Titan. The corresponding efficiency for Jupiter is only $66 \%{ }^{4}$. Measurements of the isotopic ratios of the carbon, hydrogen, nitrogen and chemically inert gases will provide important information on the evolution of the atmosphere of Titan.

2. Meteorology and Circulation

Titan's "hydrological" cycle involving the condensation, precipitation and evaporation of hydrocarbons may resemble the water hydrological cycle on Earth. The Hubble Space Telescope (HST) mapped light and dark features over the surface during a complete 16-day rotation period. The HST tracked a bright area surface feature some 2500 miles across. Calculations indicate that Titan has roughly 100 times more latent heat available for fueling weather than does the Earth's atmosphere. Recent observations of the presence of clouds that form at the tropopause are evidence for hurricane-sized cloud systems. The nature and formation of the clouds, the origin of the large storm systems, and the effects of latent heat on cloud formation and atmospheric circulation are unknown ${ }^{5,6}$.

\section{The Surface}

Visible imaging of the surface of Titan is not feasible from orbit due to the thick layers of opaque haze and clouds in the atmosphere ${ }^{6}$. Hydrocarbon lakes or oceans would serve a similar role as the lakes or oceans on the early Earth that led to the production via polymerization reactions of the first living systems. It has also been hypothesized that the tropopause of Titan acts as a "cold trap," where gaseous organic compounds condense out of the atmosphere and are, hence, removed from the atmosphere, followed by their deposition to the surface. For example, ethane precipitates out of the atmosphere onto the surface producing ponds, lakes or oceans of ethane (or ethane/methane). An ethane/methane ocean at the surface may be the source of the re-cycling of methane back into the atmosphere.

\section{B. Assumed Science Payload}

Using the science themes, a fundamental measurement set is defined. A mission architecture has been defined which includes a long duration orbital measurement set ( $\sim 3$ year life) coupled with a shorter duration in-situ measurement set mounted on an aerial vehicle ( 4 month life). Based on the mission architecture and the science goals, the mission measurement set has been selected and is identified in Table 2 for the orbiter and aerial vehicle (AV).

Measurements of the atmosphere and surface of Titan are the primary emphasis of the orbiter. Serving as the telecommunications relay from the aerial vehicle is the secondary purpose of the orbiter. The measurements taken

Table 2. Identification of Measurements

\begin{tabular}{|l|l|l|}
\hline Platform & Measurement Type & Science Objectives \\
\hline Orbiter & Solar occultation (SO) & Determine atmospheric composition and isotopic ratios \\
\hline Orbiter & Radar Mapper (RAD) & Determine nature of the surface \\
\hline Orbiter & Magnetometer (MAG) & Search for both planetary dipole and surface magnetism \\
\hline Orbiter & Ultraviolet Spectrometer (UVS) & $\begin{array}{l}\text { Measure atomic and molecular hydrogen escape from } \\
\text { the upper atmosphere of Titan }\end{array}$ \\
\hline Orbiter & $\begin{array}{l}\text { Visual and Infrared Mapping } \\
\text { Spectrometer (VIMS) }\end{array}$ & $\begin{array}{l}\text { Measure cloud layer, haze layer, and surface } \\
\text { characteristics (IR) }\end{array}$ \\
\hline AV & Aerial Vehicle Imager System (AIS) & Investigate surface features, clouds, and haze \\
\hline AV & Mass Spectrometer (MS) & Measure atmospheric composition and isotopic ratios \\
\hline AV & Haze and cloud particle detector (HCP) & Determine aerosol abundance and characterization \\
\hline AV & Surface Composition Spectrometer (SCS) & Determine nature and composition of the surface \\
\hline AV & Sun-seeking spectrometer (SSS) & Measure the opacity of the atmosphere of Titan \\
\hline
\end{tabular}


Table 3. Aerial Vehicle Instrument Summary

\begin{tabular}{|l|l|l|l|l|}
\hline Instrument & Heritage & Mass (kg) & Power (W) & Data Rate \\
\hline Aerial Vehicle Imaging System: & Clementine (UVVIS) & 1.3 & 5 & 1 Mbit/image \\
\hline Mass Spectrometer & Pioneer Venus (LCPS) & 10 & 28 & $1.5 \mathrm{kbps}$ \\
\hline Haze \& Cloud Particle Detector & Pioneer Venus (LCPS) & 2.5 & 20 & $4 \mathrm{kbps}$ \\
\hline $\begin{array}{l}\text { Surface Composition } \\
\text { Spectrometer }\end{array}$ & Messenger (MASCS) & 5 & 5 & $5 \mathrm{kbps}$ \\
\hline Sun Seeking Spectrometer & Galileo (Net Flux Radiometer) & 3 & 11 & $4 \mathrm{kbps}$ \\
\hline Surface Science Package & Huygens & 5 & 10 & unknown \\
\hline
\end{tabular}

from the orbiter and aerial vehicle will extend the Titan measurements obtained by the Cassini spacecraft and the Huygens probe. For the purposes of the study, instruments were selected that provided similar measurements to those needed to address the science questions. Many of the selected aerial vehicle instruments have heritage from previous deep-space missions. Detailed performance requirements for the instruments have not yet been derived from the science questions. However, instruments have been selected that have performed similar measurements and will provide enough data (power, mass, volume and data rate) to perform the systems study. Using either existing instruments or those which can be realized in the near term reduces the overall risk and provides the performance upper bound for each platform including the launch vehicle. The emphasis of this study was the aerial vehicle, and consequently, only the instruments associated with the aerial vehicle are described below. A summary of the Aerial Vehicle Science Instrument Package is provided in Table 3.

\section{Atmospheric Characteristics}

Titan exhibits an atmosphere which is similar to but still very different than that of Earth. Key parameters are compared between Titan and Earth in Table 4. For application to the design study for an aerial vehicle, it was necessary to have information on the change in temperature, pressure, and density with altitude, as well as possible winds. This data was compiled using the TitanGRAM program which provides for an engineering model of the atmosphere of Titan ${ }^{7}$. This data is shown in the Appendix, Table A and represents the nominal atmospheric profile.

\section{Mission Parameters and Inputs}

Understanding all aspects of the mission is needed to demonstrate the closure of the overall mission capability and provide assumptions for the aerial vehicle design study. Details of the mission, the mission elements, and the specific hardware descriptions and assumptions are provided. Implementation of the Titan Explorer Mission is baselined using a combination of existing and near term development items. In this manner, it can be seen that a realistic mission using current capabilities is achievable. Further, reductions in system mass and power as well as improvements in efficiencies of power systems, communications systems, as well as launch vehicle capabilities serve only to further enhance this mission. Enabling capabilities are limited to those which provide a significant mass savings or performance enhancement. Aerocapture at Titan and the use of second generation radioisotope thermoelectric generators (RTG's) are the primary enabling technologies used.

A variety of simplifying assumptions were made throughout the study. Identification of the assumptions and the supporting rationale are provided in Table 5 and are based on the earlier mission architecture and aerocapture study in Ref. 9. While launch opportunities exist every year, it is judged that launch should occur in the Spring of 2018 to provide sufficient time for the lower TRL technologies to mature while ample time for the recent Cassini-Huygens observations to be fully exploited by the science community prior to committing a mission architecture for a new mission. Use of either an Atlas V-551 or a Delta IV-Heavy (4040-H) provides sufficient capability to inject into the

Table 4. Comparison of Earth and Titan ${ }^{8}$

\begin{tabular}{|l|l|l|}
\hline Parameter & Earth & Titan \\
\hline Diameter & $12,756 \mathrm{Km}$ & $5150 \mathrm{Km}$ \\
\hline Gravity & $980 \mathrm{~cm} / \mathrm{sec}^{2}$ & $135 \mathrm{~cm} / \mathrm{sec}^{2}$ \\
\hline Average Surface Temperature & $288 \mathrm{~K}$ & $93 \mathrm{~K}$ \\
\hline Average Surface Pressure & $1 \mathrm{bar}$ & $1.5 \mathrm{bars}$ \\
\hline Average Surface Density & $1.24 \mathrm{~kg} / \mathrm{m}^{3}$ & $5.75 \mathrm{~kg} / \mathrm{m}^{3}$ \\
\hline Primary Atmospheric Constituents & $\mathrm{N} 278 \% ; \mathrm{O} 221 \%$ & $\mathrm{~N} 297 \% ; \mathrm{CH} 43 \%$ \\
\hline Average Surface Speed of Sound & $319 \mathrm{~m} / \mathrm{s}$ & $181 \mathrm{~m} / \mathrm{s}$ \\
\hline
\end{tabular}


initial transfer orbit. The system is sized to fit within a 4 meter diameter launch fairing (3.75 m outer diameter aeroshell; approximately $3.5 \mathrm{~m}$ inner diameter envelope). The complete launch stack consists of the aerial vehicle contained inside its own entry aeroshell, an orbiter also contained inside of an aeroshell of the same dimensions, a transfer propulsion module, and an intermediate support structure for interconnecting all of the elements as well as connecting to the launch vehicle. Solar Electric Propulsion (SEP) is used to provide the continuous low thrust transfer to Titan (transfer propulsion module). A single Earth Gravity Assist (EGA) increases the transfer energy level ensuring the system can fit within existing launch vehicle capabilities. After the spacecraft achieves a distance between 4.0 and 5.0 Astronomical Units (AU), the SEP propulsion module is released. Seven (7) days prior to arrival at Titan, the aerial vehicle contained inside its entry aeroshell is released for a direct entry into the atmosphere of Titan. The orbiter, still inside its aeroshell, performs a divert maneuver, as it is initially on a direct impact trajectory to Titan, to align itself for the data relay for the aerial vehicle critical events as well as to provide the initial targeting for aerocapture. The aerial vehicle performs a direct entry where it is then extracted and transitions to its normal flight configuration. After receipt of the aerial vehicle critical events data, the spacecraft then performs its final targeting trajectory correction maneuver (TCM) for the aerocapture. The orbiter is captured into its orbit and sheds its aeroshell. At this time, the orbiter performs any final maneuvers to put itself in its preferred orbit while the aerial vehicle begins its mission operations. Flight between 1 and $5 \mathrm{~km}$ above the surface is considered the flight envelope for the aerial vehicle, but surface interaction is desired, either by landing, use of a deployable probe, or both.

\section{Atmospheric Vehicle Options}

Investigation of possible platforms for the aerial survey of Titan concentrated on three traditional vehicles: the airplane, the airship (lighter-than-atmosphere vehicle), and the helicopter. While the airplane and airship were explored in detail, the helicopter was only briefly surveyed. The feasibility and subsequent conceptual design of a Titan helicopter was delegated to a group of students at the Guggenheim School of Aerospace Engineering at Georgia Institute of Technology. It is conceded that other, less traditional aerial platforms (such as aerobots, aerorovers, and other floating vehicles) could be adapted for the exploration of Titan, but in the interest of simplicity and practicality, the scope of the investigation was kept to well-tested, traditional platforms. A preliminary investigation into propulsive power required provided initial insight into the advantages and disadvantages of each platform with regard to one of the major challenges of operating a long-duration mission on Titan - power available. Preliminary designs and, finally, an operational concept applied to flight on Titan were developed for the airplane and airship to allow direct comparison of these two platforms.

\section{A. Propulsive Power Comparison}

The distance from Earth to Titan, and consequently its relative distance from the Sun, dictates that the amount of useful power delivered to Titan would be one of the central issues facing any planetary exploration platform. Power

Table 5. Mission Assumptions

\begin{tabular}{|l|l|l|}
\hline No. & Assumption & Rationale \\
\hline 1 & Launch in 2018 & $\begin{array}{l}\text { Allows newer technologies to be developed. Allows } \\
\text { full evaluation of Cassini-Huygens data. }\end{array}$ \\
\hline 2 & Technology cutoff (TRL-6) in 2014 & Typical assumption - launch minus 4 years \\
\hline 3 & No special planetary protection provisions & Consistent with current NASA policy. \\
\hline 4 & $\begin{array}{l}\text { Titan orbit insertion performed via } \\
\text { aerocapture. }\end{array}$ & Reduces total launch mass \\
\hline 5 & Low thrust solar electric propulsion to Titan & $\begin{array}{l}\text { Reduces total launch mass. Eliminates need for large } \\
\text { launch vehicle. Eliminates need for nuclear propulsion. }\end{array}$ \\
\hline 6 & Single Earth Gravity Assist & $\begin{array}{l}\text { Reduces total launch mass. Earth provides larger } \Delta \text { V } \\
\text { increment than Venus. }\end{array}$ \\
\hline 7 & $\begin{array}{l}\text { X-band as primary data return to Earth } \\
\text { or optical are enhancing. }\end{array}$ \\
\hline 8 & $\begin{array}{l}\text { Total radiation dose of 25 krads behind 100 } \\
\text { mils of aluminum with an RDM of 2. }\end{array}$ & From JPL Team-X Evaluation of Titan Explorer \\
\hline 9 & $\begin{array}{l}\text { Use TitanGRAM as the engineering model of } \\
\text { the atmosphere. }\end{array}$ & See Ref. 7 \\
\hline 10 & Entry Aeroshell & $\begin{array}{l}\text { 3.75 m diameter, biconic shape with a 70-degree } \\
\text { sphere cone forebody }\end{array}$ \\
\hline
\end{tabular}


will be supplied to the aerial platform via a certain number of radioisotope thermal electric generators (RTG's). The use of RTG's has been shown to be effective on many spacecraft destined for the outer planets where solar power is not viable, such as Pioneer 10 and 11, Voyager 1 and 2, Ulysses, Galileo, and most recently, Cassini ${ }^{10}$. For the NASA Vision Missions Study, a set of current and second-generation RTG parameters were made available, as can be seen in Table 6, based on current development activities of the US Department of Energy and NASA ${ }^{11,12}$.

A basis of comparison for each of the three candidate aerial platforms was required to properly assess their power requirements, especially in the area of propulsive power required. Due to the desire for a long duration aerial

Table 6. Radioisotope Thermoelectric Generator Options

\begin{tabular}{|c|c|c|c|c|}
\hline Parameter & MMRTG & SRG & $\begin{array}{c}\mathbf{2}^{\text {nd }} \text { Gen. } \\
\text { MMRTG }\end{array}$ & $\begin{array}{c}\mathbf{2}^{\text {nd }} \text { Gen. } \\
\text { SRG }\end{array}$ \\
\hline Power (W) & $\begin{array}{c}120(\mathrm{BOL}) \\
110(\mathrm{EOL})\end{array}$ & $\begin{array}{c}114(\mathrm{BOL}) \\
95(\mathrm{EOL})\end{array}$ & $\begin{array}{c}120(\mathrm{BOL}) \\
110(\mathrm{EOL})\end{array}$ & $\begin{array}{c}114(\mathrm{BOL}) \\
95(\mathrm{EOL})\end{array}$ \\
\hline Specific Power (W/kg) & 4.12 & 4.22 & $8-10$ & $8-10$ \\
\hline Mass (kg) & 34 & 27 & 17 & 14 \\
\hline Voltage (VDC) & $28 \pm 0.2$ & $28 \pm 0.2$ & $28 \pm 0.2$ & $28 \pm 0.2$ \\
\hline Lifetime (yrs) & $\begin{array}{c}10-14 \\
\text { (space) }\end{array}$ & $\begin{array}{c}10-14 \\
\text { (space) }\end{array}$ & $\begin{array}{c}10-14 \\
\text { (space) }\end{array}$ & $\begin{array}{c}10-14 \\
\text { (space) }\end{array}$ \\
\hline Availability & 2009 & 2009 & 2013 & 2013 \\
\hline Pu-238 Content $(\mathrm{kg})$ & 4 & 1 & 4 & 1 \\
\hline $\begin{array}{c}\text { Thermal Efficiency } \\
\left.\text { (\% - } \mathrm{W}_{\text {elec }} / \mathrm{W}_{\text {therm }}\right)\end{array}$ & $7 \%$ & $24 \%$ & $7 \%$ & $24 \%$ \\
\hline
\end{tabular}

survey, it is assumed for this study that the method of locomotion for each platform is electrically based (as opposed to a rocket or a jet burning methane from the atmosphere), with most likely a propeller or rotor as the propulsor. For this, formulas developed in Ref. 13 (Eqs. 1-3) by Lorenz can be used to accurately assess the power required for each of the three platforms based on a given set of atmospheric and planetary characteristics ( $\rho$ for density, $g$ for gravity; a subscript $e$ denotes the value for Earth), a mass $(m)$, and a cruise flight velocity $(V)$. The airship and airplane formulas are based on historical data compiled on terrestrial platforms, but the equations were developed in such a way as to allow application to other planetary atmospheres. With this in mind, the variable $n$ is used as a value to parameterize the density scaling of propulsive efficiency, where $0<n<1$ (where $n=0$ is no effect on propulsive efficiency and 1 is the theoretical inverse square root effect based on actuator disk theory for propellers). For the helicopter, the formula is based on a modified actuator disk equation for a helicopter in hover applied to terrestrial helicopter installed powers. In each case, Lorenz showed that the equations predict power requirements that compare to the installed power of many platform designs quite favorably to zeroth-order (adequate for initial power comparisons).

$$
\begin{gathered}
P=10.9 m^{0.8} V^{0.9}\left(g / g_{e}\right)\left(\rho / \rho_{e}\right)^{-0.5 n} \quad \text { (Airplane) } \\
P=3.0 m^{0.6} V^{1.85}\left(\rho / \rho_{e}\right)^{0.33-0.5 n} \quad \text { (Airship) } \\
P=100 m^{1.1}\left(g / g_{e}\right)^{1.5}\left(\rho / \rho_{e}\right)^{0.5} \text { (Helicopter) }
\end{gathered}
$$

Using these equations, it is possible to examine the power requirements for a Titan aerial platform in the expected payload delivery range of approximately $300-400 \mathrm{~kg}$. The results for the airship (Figure 2) show it will not be able to fly much greater than about $5 \mathrm{~m} / \mathrm{s}$ without inducing a huge propulsive power requirement. Even more pertinent is that the airplane results (Figure 1) show that even at low speeds in the $10 \mathrm{~m} / \mathrm{s}$ range, the power 
requirements become extreme enough (based on the RTG power output to mass ratio) so as to be impractical. From a design perspective, this information indicates that while the airship would be operating at a cruise velocity reasonably close to its terrestrial equivalents (for example, the Bosch Aerospace SASS-LITE remotely-piloted airship has a maximum speed of approximately $20 \mathrm{~m} / \mathrm{s}$ ), the airplane would be in a very low-velocity regime compared to commonly operated powered aircraft. The helicopter power-to-hover (1360 W at $300 \mathrm{~kg}$ and $1867 \mathrm{~W}$ at $400 \mathrm{~kg}$ ), as might be expected, is higher than the airship operating at less than approximately $4 \mathrm{~m} / \mathrm{s}$ with $n=1$, but interestingly is approximately equivalent to the airplane operating at $6 \mathrm{~m} / \mathrm{s}$ with $n=1$. As Lorenz explains, the helicopter benefits much more from the both the reduced gravity and higher density on Titan than the airplane or airship. This suggests, based solely on power requirements, that the helicopter is a very competitive alternative to the airship or airplane.

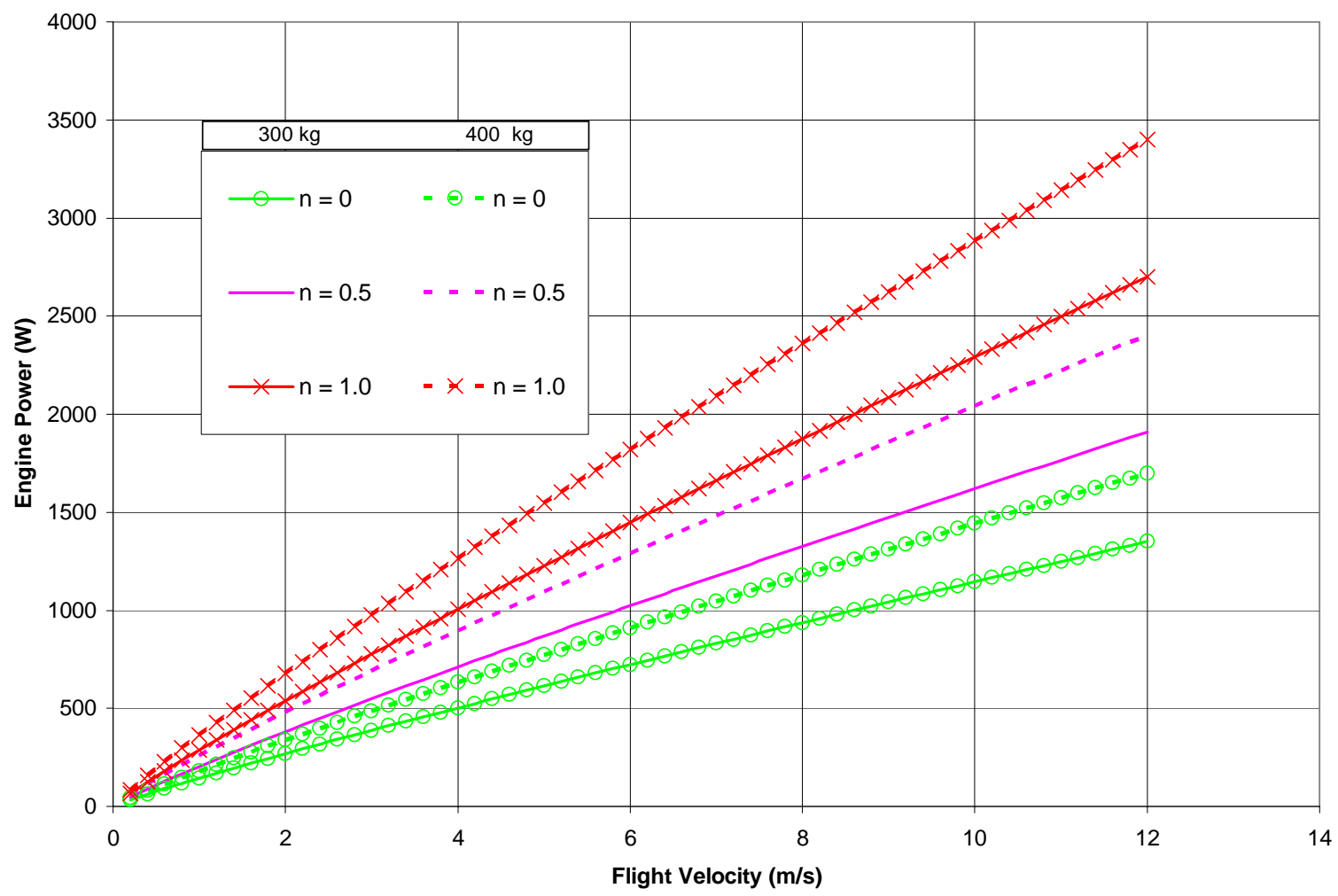

Figure 1. Flight Velocity vs. Engine Power, Titan Airplane 


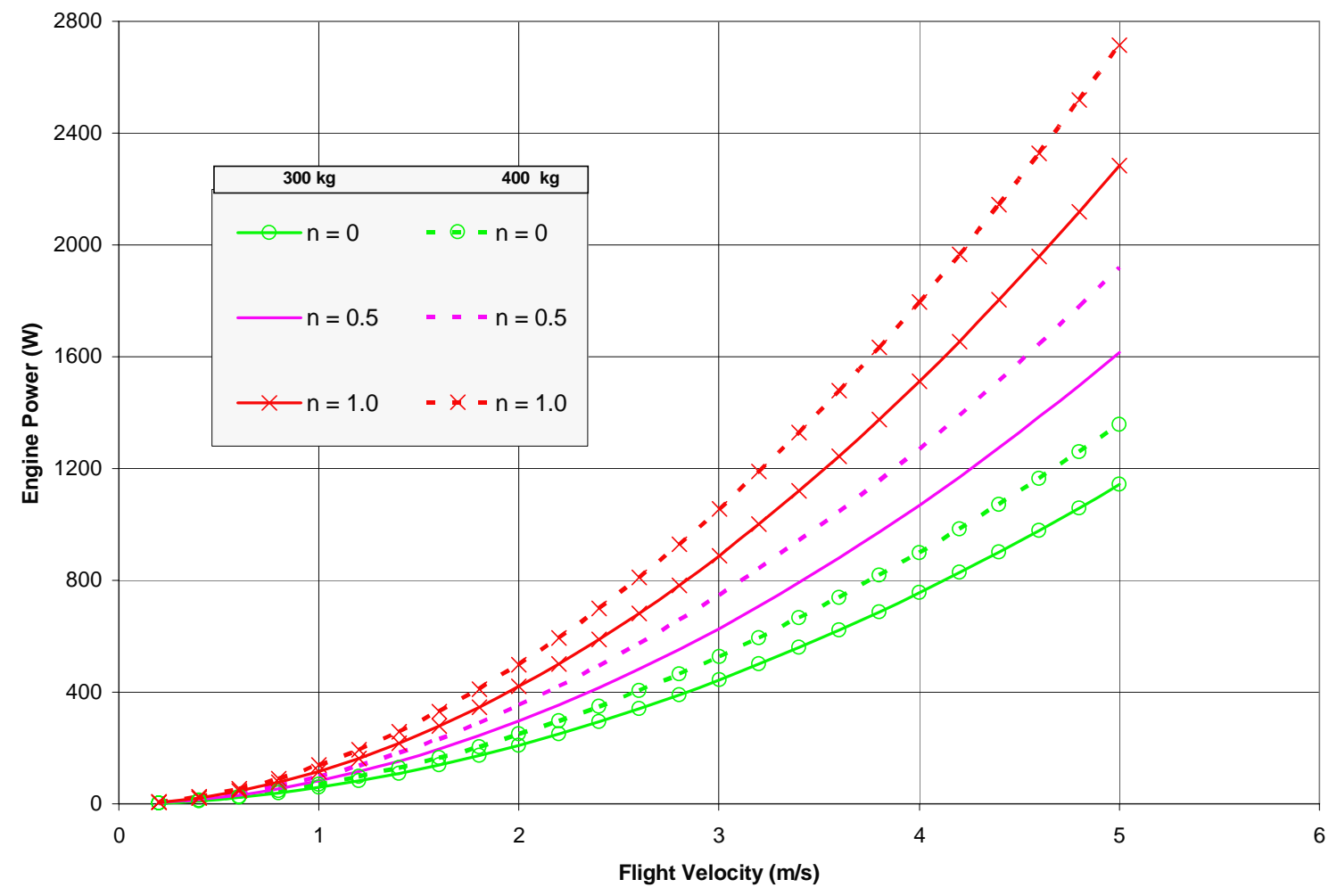

Figure 2. Flight Velocity vs. Engine Power, Titan Airship

\section{B. Preliminary Designs}

Using the preliminary power requirements, science goals, assumed payload constraints, and the target total mass budget of $300-400 \mathrm{~kg}$, preliminary designs of the airplane and airship could be formulated. As mentioned above, the helicopter was not carried past the initial power comparison to the design stage as part of the authors' work, but was completed as a separate part of the study ${ }^{14}$. Continuing with the airship and airplane, designs were developed using basic equations, as well as mass estimates based on assumed subsystem values (such as for the telecommunications subsystem) where available or, if specific values were unavailable, historically-based applicable values. These designs were carried through to a preliminary stage such that both quantitative and qualitative comparisons could be effectively made.

\section{Airplane}

For the airplane, historical subsystem mass data was complied on various terrestrial airplanes in the applicable mass range. Unfortunately, information on unmanned and/or miniature airplane mass breakdowns in this range is not readily available, especially in a reliable and consistent format. However, information can be culled on manned aircraft with masses of less than $2000 \mathrm{~kg}$ from available literature to provide a preliminary estimate and assist in the design formulation. Table 8 shows the mass fraction data for relevant airplane subsystem components, both with a computed mean for each subsystem and a standard deviation. These terrestrial aircraft represent vehicles designed for such varied functions as homebuilt hobby vehicles (BD 5B) to single and twin propeller-driven multi-passenger vehicles. Since none of these terrestrial aircraft operate with electrically-based propulsion, their mass fraction data cannot be directly applied to this design for every subsystem. However, in the case of components such as the propeller, structure, avionics/flight controls, and electrical, these numbers can be used to provide a preliminary mass estimate of each corresponding major subsystem on a Titan aircraft based solely on the total mass available, defined as a constraint above. With this information, an estimate can be made of the total amount of mass left that can be devoted to the power subsystem (RTG's and batteries; power distribution is assumed to be part of the electrical subsystem). Consequently, if the power available can be calculated, it can be combined with other study constraints (such as aeroshell diameter, deployment risk, and flight regime) to produce a rudimentary description of the design for a Titan aircraft. 
Table 8. Subsystem Mass Fractions Data

\begin{tabular}{|c|c|c|c|c|c|c|c|c|c|}
\hline Name & $\begin{array}{c}\text { Total } \\
\text { Mass } \\
(\mathbf{k g})\end{array}$ & Payload & Engine & Propeller & Fuel & $\begin{array}{c}\text { Fuel } \\
\text { System }\end{array}$ & $\begin{array}{c}\text { Avionics } \\
\text { \& } \\
\text { Controls }\end{array}$ & Electrical & $\begin{array}{c}\text { Landing } \\
\text { Gear }\end{array}$ \\
\hline BD 5B & 476.6 & 0.162 & 0.148 & 0.005 & 0.324 & 0.024 & 0.014 & 0.010 & 0.030 \\
\hline Cessna 150 & 680.2 & 0.265 & 0.150 & 0.015 & 0.104 & 0.011 & 0.023 & 0.023 & 0.069 \\
\hline Cessna 172 & 997.6 & 0.319 & 0.132 & 0.015 & 0.115 & 0.010 & 0.016 & 0.017 & 0.050 \\
\hline Cessna 175 & 1065.6 & 0.306 & 0.151 & 0.014 & 0.133 & 0.011 & 0.015 & 0.016 & 0.047 \\
\hline Cessna 180 & 1201.6 & 0.277 & 0.171 & 0.024 & 0.147 & 0.010 & 0.016 & 0.016 & 0.042 \\
\hline Cessna 182 & 1201.6 & 0.270 & 0.171 & 0.024 & 0.147 & 0.010 & 0.016 & 0.016 & 0.050 \\
\hline Cessna L-19A (military) & 952.2 & 0.153 & 0.220 & 0.022 & 0.120 & 0.019 & 0.040 & 0.060 & 0.064 \\
\hline Beech J-35 & 1315.0 & 0.291 & 0.149 & 0.025 & 0.081 & 0.010 & 0.025 & 0.025 & 0.071 \\
\hline Rockwell 112TCA & 1339.5 & 0.251 & 0.161 & In Engine & 0.078 & 0.006 & 0.037 & 0.027 & 0.055 \\
\hline Cessna 210J & 1541.7 & 0.204 & 0.132 & 0.019 & 0.136 & 0.007 & 0.019 & 0.017 & 0.056 \\
\hline Beech 95 TA & 1813.7 & 0.183 & 0.130 & 0.041 & 0.168 & 0.021 & 0.031 & 0.024 & 0.055 \\
\hline Cessna 310C & 2190.1 & 0.246 & 0.176 & 0.034 & 0.127 & 0.016 & 0.023 & 0.025 & 0.054 \\
\hline
\end{tabular}

Assuming a total mass at the lower end of the available mass range (300 kg), Table 7 shows a mass buildup for a Titan aircraft, with both the mass fraction of the subsystem and the subsequent actual subsystem mass. The avionics/flight controls mass fraction is a value based on the data obtained for actual components which would be used on this system (as seen in the Appendix, Table B). These components were specified during the conceptual design of the airship, but are applicable to the airplane, with minor changes that would have a negligible effect on subsystem mass. The electrical subsystem is again a $3-\sigma$ high value based on Table 7 due in large part to an assumed higher percentage of electrical components related to the propulsion system and science instrument package. Propeller mass is derived from the mean value from Table 7. Related to the propeller, the motor/gearbox/drivetrain subsystem is a 3- $\sigma$ low value due in large part to the use of a less complex electricallybased propulsion system (although, this is balanced by an increase in the electrical subsystem) rather than a combustion-based system. The thermal subsystem is an estimate based on preliminary thermal packaging designs for the ARES Mars airplane ${ }^{15}$ and would include heaters and multi-layer insulation. Additional thermal control system items would be included in the structural subsystem mass. The telecommunications subsystem is based on the best-estimate mass of the assumed UHF radio, plus its antenna and associated support hardware. Battery mass is derived from a preliminary power system optimization done on the power system of the airship, but because the same science instruments and, most likely, the same data relay scheme would be employed for the airplane, the depth of discharge and peak power level estimates are essentially the same. The dropsonde package is a budgeted $5 \mathrm{~kg}$ science package that will be dropped to the surface to accomplish some method of surface interaction. The structure subsystem is based on data from Table 7 and additional data from the ARES Mars airplane preliminary design ${ }^{16}$. Assuming use of the $2^{\text {nd }}$ Generation SRG from Table 6, with the remaining mass (70.4 kg), it would be possible to carry at most 5 SRG's. However, due to likely volume limitations, thermal waste heat concerns, and desire to preserve a category for miscellaneous items in the mass breakdown, it was decided to limit the aircraft to 4 SRG's, thus

Table 7. Titan Aircraft Subsystem Mass Breakdown

\begin{tabular}{|c|c|c|}
\hline Subsystem & $\begin{array}{c}\text { Assumed } \\
\text { Mass } \\
\text { Fraction }\end{array}$ & Mass (kg) \\
\hline Avionics \& Flight Controls & $12.1 \%$ & 36.4 \\
\hline Electrical & $5.0 \%$ & 15.0 \\
\hline Propeller(s) & $2.2 \%$ & 6.5 \\
\hline Motor/Gearbox/Drivetrain & $8.2 \%$ & 24.7 \\
\hline Thermal & $3.3 \%$ & 10.0 \\
\hline Telecom & $9.6 \%$ & 28.7 \\
\hline Batteries & $2.9 \%$ & 8.6 \\
\hline Dropsonde Package & $1.7 \%$ & 5.0 \\
\hline Payload & $8.2 \%$ & 24.5 \\
\hline Structure & $28.2 \%$ & 84.7 \\
\hline Total Mass & $\mathbf{1 0 0 . 0} \%$ & $\mathbf{3 0 0 . 0}$ \\
\hline Remaining Mass (RTGs) & $\mathbf{1 8 . 7} \%$ & $\mathbf{5 6 . 0}$ \\
\hline
\end{tabular}


Table 9. Maximum Flight Velocity, Titan Airplane

\begin{tabular}{|c|c|c|c|c|}
\hline L/D & $\begin{array}{c}\text { Weight } \\
\text { (N) }\end{array}$ & $\begin{array}{c}\text { Total } \\
\text { Prop } \\
\text { Efficiency }\end{array}$ & $\begin{array}{c}\text { Power } \\
\text { Avail (W) }\end{array}$ & $\begin{array}{c}\text { Max } \\
\text { Velocity } \\
\text { (m/s) }\end{array}$ \\
\hline 10 & 406.2 & 0.637 & 209 & $\mathbf{3 . 2 8}$ \\
\hline 12 & 406.2 & 0.637 & 209 & $\mathbf{3 . 9 3}$ \\
\hline 16 & 406.2 & 0.637 & 209 & $\mathbf{5 . 2 4}$ \\
\hline 18 & 406.2 & 0.637 & 209 & $\mathbf{5 . 9 0}$ \\
\hline 22 & 406.2 & 0.637 & 209 & $\mathbf{7 . 2 1}$ \\
\hline
\end{tabular}

providing $56 \mathrm{~kg}$ total for the SRG's and a miscellaneous item category accounting for the remaining $14.4 \mathrm{~kg}$.

Using the information from Table 6 for end of life (EOL) values of the power output of 4 SRG's, the total available power to the airplane would be $380 \mathrm{~W}$. Utilizing the aforementioned power system optimization, the constant power required for the operation of the non-propulsive elements (including the science instruments) would be $171 \mathrm{~W}$, thus leaving a maximum of $209 \mathrm{~W}$ for propulsion. However, this power is the raw power delivered to the propulsion system and does not include inefficiencies in the propeller $\left(\eta_{p}\right)$, control electronics $\left(\eta_{e}\right)$, motor $\left(\eta_{m}\right)$, and gearbox $\left(\eta_{g}\right)$. The total efficiency of the propulsion system, $\eta_{t}$, is then given by Eq. (4).

$$
\eta_{t}=\eta_{p} \eta_{e} \eta_{m} \eta_{g}
$$

Representative values for the elements of this equation were derived for use in study on Mars airplane propellers ${ }^{17}$, with $\eta_{\mathrm{p}}=0.85, \eta_{\mathrm{e}}=0.98, \eta_{\mathrm{m}}=0.90$, and $\eta_{\mathrm{g}}=0.85$. This produces a total propulsive efficiency of 0.637 , and leaves a maximum useful propulsive power of $133.1 \mathrm{~W}$.

Knowing the useful power available to propel the aircraft leads directly to the maximum steady, level flight velocity. The flight velocity of the Titan airplane is one of its defining characteristics and one which can allow an effective comparison with the airship and helicopter. To derive the feasible velocity range of the airplane, it is necessary to define the relationship between propulsive power and flight velocity. To begin, we must assume the condition of level and steady flight which leads to the assumption that the lift force of the airplane would equal its weight $(L=W)$ and the total drag force acting on the vehicle would be counteracted by the propulsive thrust $(D=$ $T$ ). Combining these equations yields a relationship between the lift-to-drag ratio of the airplane and the thrust as seen in Eq. (5). Further, the theoretical thrust power equation can be used in its modified version as given in Eq. (6), while utilizing the previously defined value for total propulsive efficiency from above, to produce Eq. (7) which is a relation between propulsive power required and flight velocity. This equation includes a definable vehicle quality (weight) and a general performance value (lift-to-drag ratio) often used during the conceptual design phase. This equation can be graphed to show propulsive power versus steady, level flight velocity for different values of $L / D$ (see Figure 3). Using this equation with the previously defined raw propulsive power available (209 W) and differing sets of L/D, values for the maximum steady, level flight velocity can be found, as seen in Table 9 (the weight is based on $300 \mathrm{~kg}$ vehicle at the Titan gravity).

$$
\begin{gathered}
T=W /(L / D) \\
\eta_{t} P_{r e q}=T V \\
P_{r e q}=\left(1 / \eta_{t}\right)\left[\frac{W}{(L / D)}\right] V
\end{gathered}
$$




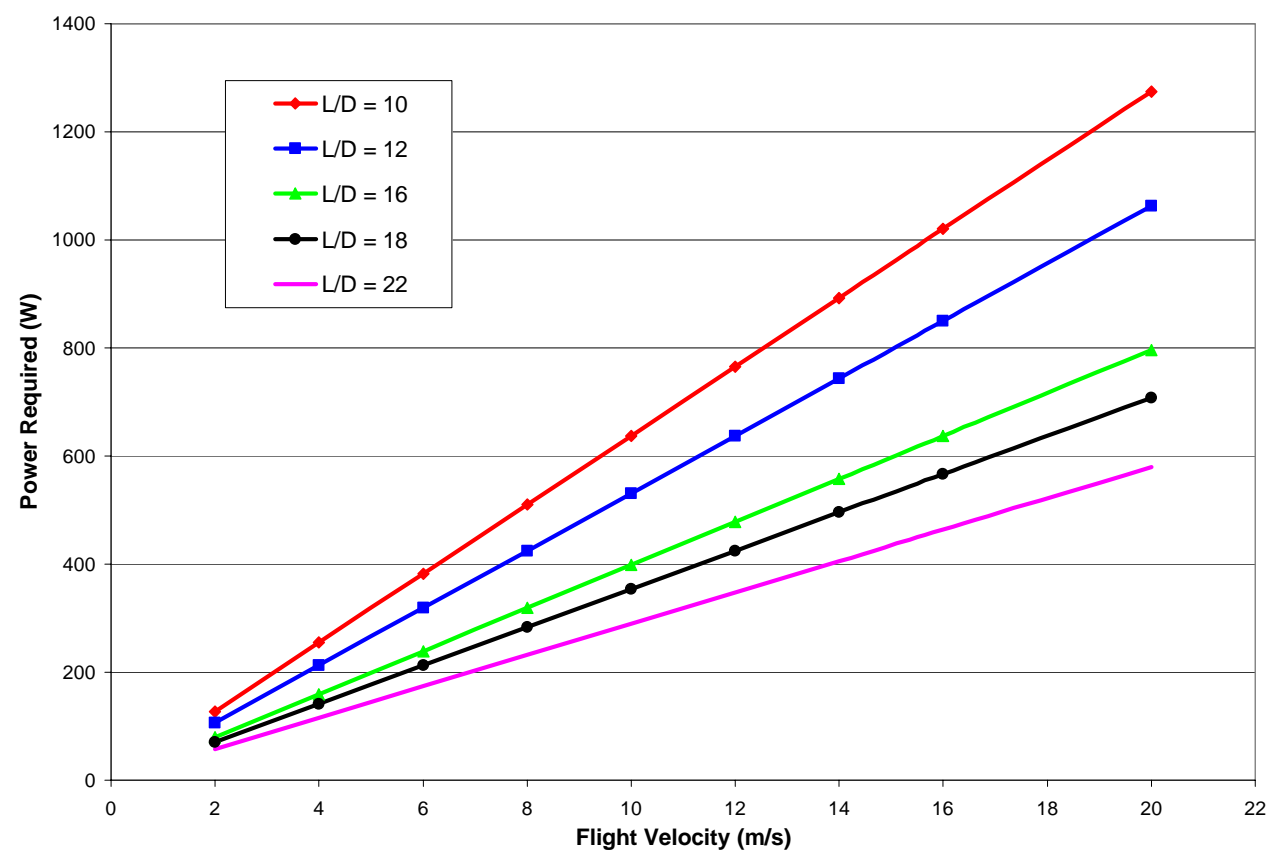

Figure 3. Flight Velocity vs. Power Required for Various L/D

As a final piece of the conceptual Titan airplane design, we can define an applicable range of wing aspect ratio $(A R)$, which is related to $L / D$ in many ways. Knowledge of the aspect ratio, along with the previously defined values for $L / D$, weight, propulsive power, and maximum velocity, will provide a set of physical parameters that can be a springboard for further detailed designs. The lift equation, Eq. (8) below, is used as the starting point, with $C_{L}$ being the three-dimensional lift coefficient and $S$ being the total wing planform area. Looking closely at the definition for planform area, we can show that span $(b)$ and aspect ratio can be substituted into the lift equation from Eq. (9), and by again setting lift equal to weight and rearranging, Eq. (10) is realized. Equation (10) can be graphed with aspect ratio versus flight velocity if the span and lift coefficient are known. For the span, it is known from Section D above that the maximum inner diameter of the entry aeroshell is approximately $3.5 \mathrm{~m}$. Based on risk evaluation from the ARES vehicle, including more than two folds in the wing per full span (one per half span) induced undesired deployment risk. With this information, the span was assumed to be a maximum of three times $3.5 \mathrm{~m}$, or $10.5 \mathrm{~m}$. This value implies the outboard folded wing sections would have space within the aeroshell to span its maximum diameter; thus this total span represents an upper limit for this number of folds. However, since ultimately the optimum span may not be the maximum, a determination of the range of AR versus maximum flight velocity must include different span lengths. In addition, it is useful to examine this relationship for different values of cruise lift coefficient. The plots of Eq. (10) in Figure 4 show curves for three different values of span length for cruise $C_{L}$ of 1.0 and 1.5. At the maximum steady, level flight velocity as shown in Table 9 above of $7.2 \mathrm{~m} / \mathrm{s}$, this plot shows a range in aspect ratio from approximately 11 for a span of $6 \mathrm{~m}$ with a $C_{L}$ of 1.0 to beyond 30 for longer spans and higher $C_{L}$. Combining this information with the high L/D required if speeds greater than $6 \mathrm{~m} / \mathrm{s}$ are desired means that higher aspect ratios (and consequently lower wing areas for a given span) would most likely be preferred in order to reduce drag, especially induced drag given the low flight velocity range. Of course, this would need to be weighed against the issue of profile drag created by differing chord lengths and taper ratios, Reynolds numbers effects, wing loading, and structural considerations.

$$
\begin{gathered}
L=1 / 2 \rho V^{2} S C_{L} \\
A R=b^{2} / S
\end{gathered}
$$




$$
A R=\left[\frac{b^{2} \rho C_{L}}{2 W}\right] V^{2}
$$



Figure 4. Aspect Ratio vs. Flight Velocity, 300 kg Titan Airplane, varied span

\section{Airship}

Historical mass breakdowns for airships are less readily available than for airplanes, but the basic design of an airship can be derived directly from the basic equations of aerostatics. For an airship, the key components would include the airship hull (comprised of the lift gas, the gas envelope, the ballonets for altitude control, the tail for stability, and the internal support structure), the subsystems (very similar to the airplane), and the science payload. In the case of the lifting gas, a comparison of both helium and hydrogen as the lift gas for Titan was performed. With its lower molecular weight than helium, hydrogen was thought to provide the potential for a significantly lighter system. Results of the analysis indicated that using hydrogen would reduce the overall float mass of the airship by about $15 \%$. While this value appears significant, there is a more fundamental reason why helium was ultimately selected as the lift gas. The science from the airship includes a mass spectrometer whose role is to investigate a wide range of species. Since the lift envelope is not totally impermeable to hydrogen, some would leak out and potentially corrupt the science measurements.

Once the lifting gas was known, the sizing of the airship's hull envelope could proceed. The main component of lift for a conventional airship is the force of buoyancy, or the difference in densities of the gas contained within the envelope of the airship and the atmosphere which surrounds it. The envelope of an airship is generally considered the gasbag only since the gondola generally is not sealed with respect to the atmosphere. The gross lift $\left(L_{g}\right)$ of a given airship is therefore the total weight of the atmosphere displaced by the envelope, or the total envelope volume multiplied by the density of the atmosphere (and also multiplied by gravity if using metric densities). The net lift $\left(L_{n}\right)$, then, is the gross lift minus the weight of the contained gases within the total gasbag volume $\left(V_{g}\right.$, or gross volume). Since atmospheric density varies with altitude, however, it is necessary to incorporate a method of altitude control. The most common method for accomplishing this is with ballonets. Ballonets are separate envelopes housed within the main envelope which inflate and deflate to allow the airship to descend or ascend. Airship designs can incorporate a single ballonet or multiple ballonets. The use of multiple ballonets allows trimming of the airship with respect to the center of gravity $(\mathrm{cg})$ and for small airships ( $<50,000 \mathrm{~m}^{3}$ enclosed envelope volume) two ballonets are common, usually placed in fore and aft positions ${ }^{18}$. The ballonets are inflated with the external atmosphere to cause the airship to descend to a point at which the enclosed lift gas weight ( $V_{n}$, net volume) is again 
Table 10. Airship Hull System Mass Breakdown

\begin{tabular}{|l|l|l|l|}
\hline Description & $\begin{array}{l}\text { CBE } \\
\text { Mass } \\
(\mathrm{kg})\end{array}$ & Contingency & $\begin{array}{l}\text { ME } \\
\text { Mass } \\
(\mathrm{kg})\end{array}$ \\
\hline Gasbag Mass & 31.3 & $51.2 \%$ & 47.3 \\
\hline Ballonets (2) & 6.2 & $51.2 \%$ & 9.4 \\
\hline Airline & 0.9 & $51.2 \%$ & 1.4 \\
\hline Catenary & 4.4 & $51.2 \%$ & 6.7 \\
\hline Patches/Reinforcement & 1.6 & $51.2 \%$ & 2.4 \\
\hline Suspension System & 2.0 & $25.5 \%$ & 2.5 \\
\hline Nose Reinforcement & 2.0 & $25.5 \%$ & 2.5 \\
\hline Other Misc. Hull items & 2.5 & $49.1 \%$ & 3.7 \\
\hline Lifting Gas & 66.3 & $25.5 \%$ & 83.2 \\
\hline Total Hull Mass & 117.2 & $35.7 \%$ & 159.1 \\
\hline
\end{tabular}

equal to the displaced volume of atmosphere ( $V_{g}$ from above) minus the inflated volume of the ballonets ( $V_{a}$, or atmospheric volume now within the gasbag). The pressure height of a given airship envelope, then, is considered the point at which the ballonets are completely deflated and $V_{n}=V_{g}$. This is the maximum density altitude at which the airship could fly.

For the Titan Explorer Mission, the gross lift mass, $L_{g}$, was considered an input. Mass is used in place of weight or force when discussing the airship sizing from here on. The gravity component, while important when equating forces for comparison with terrestrial vehicles, can be divided out in all airship sizing equations if, for example, "lift" is considered a lifted mass instead of an actual weight or force. This provides a closer link between the airship sizing and the sizing of other mission systems, such as the orbiter spacecraft, for which numbers are always quoted in terms of mass. Using $L_{g}, V_{g}$ was calculated based on an assumed maximum flight altitude on Titan of $5 \mathrm{~km}$, which equates to an atmospheric density of $4.37 \mathrm{~kg} / \mathrm{m}^{3}$ (see Appendix, Table A). As discussed above, the lifting gas for the airship was assumed to be helium. In calculating helium's density, it was assumed that the helium could be held above the atmospheric pressure at the surface throughout all operating altitudes, but the temperature was equated with the atmospheric temperature at $5 \mathrm{~km}$. A mass of the lifting gas was calculated using $V_{g}$ multiplied by the aforementioned density of helium.

One essential parameter that should be mentioned about the gasbag is the differential pressure between the lifting gas within the gasbag and the Titan atmosphere. Suggested values for most modern non-rigid terrestrial airships show that a pressure difference of $125 \mathrm{~Pa}$ is sufficient ${ }^{18}$, with a factor added to account for the maximum impinging velocity expected during flight (including wind gusts). Including this factor assuming maximum wind gusts of 30 $\mathrm{m} / \mathrm{s}$ gives a minimum pressure differential of $155 \mathrm{~Pa}$. Due to the cryogenic temperatures on Titan, as well as the higher atmospheric density, the materials chosen for the gasbag laminate would need to be able to withstand differential pressures in excess of $300 \mathrm{~Pa}$. Next, the basic shape of airship gasbag had to be chosen. A diameter to length $(d / l)$ ratio of 0.20 was chosen based on separate theoretical and experimental work ${ }^{19}$ which pointed to this approximate value as producing the lowest total drag coefficient. Based on this ratio, and the equation for a prolate spheroid, a maximum radius and half-length were found. With these values known, a surface area of the gasbag was computed. An associated gasbag mass was then found by assuming an areal density of the laminate material used for the envelope material of $250 \mathrm{~g} / \mathrm{m}^{2}$.

The other major components of the airship hull are the ballonets. As discussed earlier, it is assumed there are two ballonets, positioned fore and aft, within the gasbag. The total volume of the ballonets was found by calculating the displaced volume required at $0 \mathrm{~km}$ and subtracting it from the previously found $V_{g}$. This represents the maximum volume for the ballonets. To account for fluctuation of near-surface density in allowing the airship to maintain landing capability, a 5\% factor was included in this calculation. The ballonets were assumed to be hemispherical in shape and to have material areal density 15\% less than that of the gasbag $\left(0.212 \mathrm{~kg} / \mathrm{m}^{2}\right)$. This allowed calculation of the ballonet total mass. For the other hull related components mass was based on empirical ratios related to the total mass of the gasbag or the total envelope volume ${ }^{18}$. In all cases where a range of values were given, the maximum values were chosen for conservatism. The mass breakdown for the hull related components are presented in Table 10.

Finally, the tail, airship subsystems, and science payload were basic extensions of the same principles followed for the airplane conceptual design above. The tail and gondola were based on the enclosed hull volume and empirical data. For the propulsion subsystem, the airship was assumed to employ two propellers capable of propelling the airship at a constant $4 \mathrm{~m} / \mathrm{s}$ if both propellers were working and $3 \mathrm{~m} / \mathrm{s}$ if only one was operable. The science payload was the same set of components as the airplane. The electrical/power subsystem was based on a 4 SRG power plant, with associated power distribution systems, while the command and data subsystem (CDS) and attitude control subsystem (ACS) were based on chosen components as discussed above (as seen in Appendix, Table B). Finally, thermal and telecommunications subsystems were based on historical reference as with the airplane. The total subsystem mass breakdown appears in Table 11, while Fig. 5 shows a sketch of the airship. 


\section{Operational Concept}

Independent of the platform, the operational concept for the Titan Explorer will require either platform to navigate Titan nearly autonomously and will require robust and sophisticated navigational control. Upon extraction from the entry aeroshell and successful deployment, a certain period of the early phase of the mission will be spent exercising key systems. After this initial checkout period is complete, the nominal mission operations will proceed. The general goal of the aerial flight segment from an operational perspective is to cover as much of the surface of Titan as possible (global survey) while stopping to concentrate on interesting areas. This approach will be very similar to current Mars rover exploration plans, but on a much larger scale. An assigned path will be uploaded to the vehicle on a periodic basis - more or less frequently depending on the current activity and its requirement for ground operations input. The aerial vehicle will then proceed along this path, but will be subject to winds, especially wind gusts, in excess of its powered flight velocity. Winds obviously affect the airship greater, but the airplane, due to its relatively low flight velocity, will also need to account for winds. Thus, the assigned trajectory will have to be corrected in real-time by the on-board navigation system using the propulsion and attitude control systems. Altitude profile along the path will also be part of the assigned trajectory. This will allow the vehicle to fly at a constant altitude above the surface if required. It is expected there will also be autonomous obstacle avoidance capability within the navigation system such that the assigned altitude profile can be adjusted to account for larger than

Table 11. Airship Component Mass Breakdown

\begin{tabular}{|l|c|c|c|}
\hline \multicolumn{1}{|c|}{ Description } & CBE Mass (kg) & Contingency (\%) & $\begin{array}{c}\text { Max. Expected Mass } \\
(\mathrm{kg})\end{array}$ \\
\hline CDS & 9.4 & $20.2 \%$ & 11.3 \\
\hline ACS & 23.5 & $24.3 \%$ & 29.2 \\
\hline Telecom & 17.5 & $24.6 \%$ & 21.8 \\
\hline Thermal & 15.9 & $30.2 \%$ & 20.7 \\
\hline Airship Hull & 95.2 & $30.6 \%$ & 124.3 \\
\hline Propulsion & 14.5 & $30.3 \%$ & 18.9 \\
\hline Airship Tail & 8.4 & $51.2 \%$ & 12.7 \\
\hline Airship Gondola & 33.6 & $30.0 \%$ & 43.7 \\
\hline EPS & 64.9 & $30.0 \%$ & 84.4 \\
\hline Science & 23.1 & $23.4 \%$ & 28.5 \\
\hline Science Surface Package & 3.0 & $66.7 \%$ & 5.0 \\
\hline Total - Dry & 309.0 & $29.6 \%$ & 900.6 \\
\hline Inflation Helium & 69.2 & $30.1 \%$ & 490.6 \\
\hline Total - Wet & 378.2 & $29.7 \%$ & \\
\hline
\end{tabular}

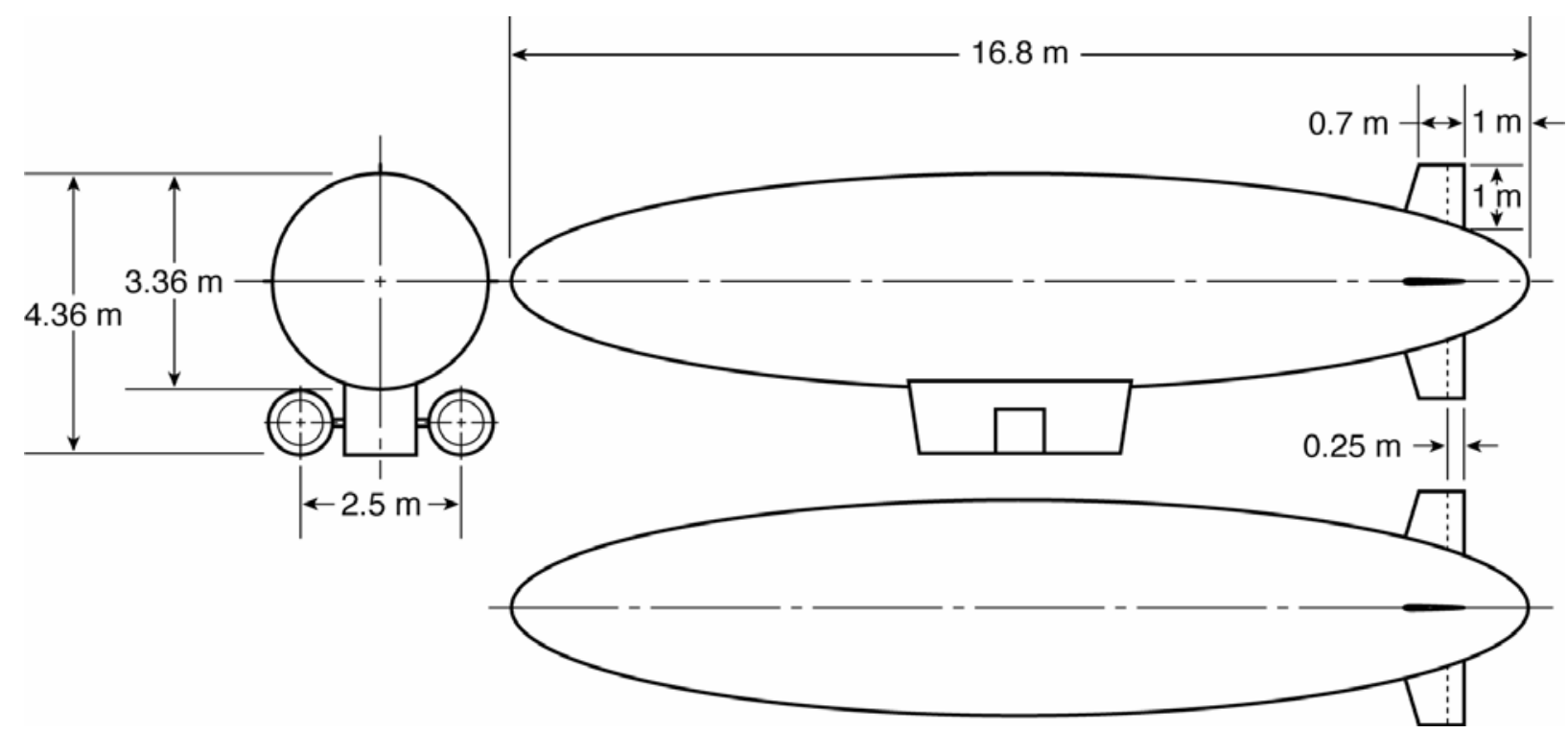

Figure 5. Airship Concept Sketch 
expected surface features.

There will be two methods for determining sites of scientific interest which will require the aerial vehicle to make a dedicated survey either by hovering over the area (for airship and if possible, given the wind speed), circling about it, or initiating a ground interaction. Prior to the uploading of the assigned path, sites along the path can be designated as "areas of interest" that will require concentrated effort. It is expected in the first instance these areas have been discovered either by prior exploration (such as interesting sites previously discovered by Cassini, the Huygens probe, or Earth-based measurements) or by the Titan orbiter. In the second instance, the aerial vehicle had discovered them on a previous pass over or near the area, and having been reviewed thoroughly by the science team on Earth, determined these areas be marked for future in-depth exploration. It is not expected the vehicle will be able to autonomously recognize areas of interest and therefore decide to concentrate on an area in real-time, although this level of autonomous technology is worth future investigation.

Upon reaching a site of interest, as has been described above, the aerial platform has three basic options. Hovering (if possible) and circling will be accomplished using the propulsion and attitude control system. However, it is possible that given winds near the surface, there may be times these options are either difficult or even impossible. In these instances, the activity may be aborted or possibly turned into a ground interaction, the third option. Landing the entire vehicle is one of the two options when referring to a ground interaction. The other option is the use of a dropsonde or deployable probe (such as a tethered probe that is retractable). In the case of the dropsonde, an area would be hovered or circled about momentarily if possible and the dropsonde released. The dropsonde would then relay information back to the airship while the airship is within range. It may be possible to outfit the dropsonde with enough transmission capability so as to reach the orbiter, but this is currently unknown. The design of a dropsonde is an area of future work related to this study. The deployable probe would be similar to the dropsonde, although it would be much less autonomous and would probably require the vehicle to hover, perhaps limiting its use to only the airship. Landing the aerial vehicle and using its on-board science instruments to take ground-based readings offers many advantages over the dropsonde or deployable probe, such as increased power and presumably larger, more sophisticated instruments, but is also a greater risk and may not be possible for the airplane (if it is desired to regain flight later).

\section{Conclusions}

Using the conceptual designs developed for the Titan airplane and airship, it is possible to compare various aspects of the platform. From this comparison, conclusions can be drawn as to what platform would be preferred to accomplish a Titan exploration mission as described in this paper. Obviously, a different set of goals for the mission might result in a different set of advantages and disadvantages. Table 12 presents a table of comparisons with a column denoting an assessment of which platform has the advantage.

Table 12. Aerial Platform Comparion

\begin{tabular}{|l|c|c|c|}
\hline \multicolumn{1}{|c|}{ Attribute } & Airplane & Airship & Advantage? \\
\hline Maximum Flight Velocity & $7+\mathrm{m} / \mathrm{s}$ & $4 \mathrm{~m} / \mathrm{s}$ & Airplane/Airship \\
\hline Deployment Risk & High & High & Neither \\
\hline Hover Capability & None & Good & Airship \\
\hline Mass (CBE) & $300 \mathrm{~kg}$ & $378.2 \mathrm{~kg}$ & Airplane \\
\hline Landing Capability & $\begin{array}{c}\text { None or once (end of } \\
\text { mission) }\end{array}$ & Multiple Possible & Airship \\
\hline Ease of Global Coverage & Medium & Medium to High & Airship \\
\hline Design Heritage & Low & Medium to High & Airship \\
\hline
\end{tabular}

In comparing the airplane and the airship, the issue of flight velocity relates to the ability to counteract winds and the ability to reach designated special targets. The airplane has the advantage in raw flight speed, but based on the winds aloft at 1 to $5 \mathrm{~km}$, the winds are sufficiently strong so the slow moving airship, and the nearly as slow airplane, would need to move mostly with the winds to achieve global coverage. If the winds are followed and not fought against, the airship is the more advantageous platform. Both platforms have risks in terms of deployment, and at this point in the assessment, are judged to be nearly equal. If a hover capability is desired, the airship is by far the best choice, although the airplane may be able to circle the area of interest and provide a small amount of station keeping in this way. The airplane has a mass advantage over the airship based on an equal amount of payload, although the level of detail in the development of the hull group of the airship (the most massive subsystem), due to 
its simplicity, is greater than the airplane structural subsystem. If a more detailed assessment of the airplane structure were undertaken, it may indeed show that the airplane is more massive relative to the airship. In terms of landing capability, the airship should be able to touch down several times because of its vertical take-off ability, whereas the airplane may be able to make one final landing at the end of the mission, unless some type of vertical take-off system were similarly pursued (but with added complexity). Both platforms have the ability to use a dropsonde or deployable probe. Global coverage, as discussed above, is conceivably slightly easier to obtain using the airship than the airplane due to the ability of the airship to float with the winds. Finally, and perhaps the most significant advantage of the airship over the airplane, is the design heritage of the airship versus the airplane. The airship, even though it is operating on an entirely different planet in a different atmosphere, is essentially the same non-rigid, helium-based system as would be seen on Earth. The airplane, as we have seen, borders on the fringe of common powered airplanes in service on Earth. For example, the airplane would be a high L/D vehicle, with more than likely high aspect ratio wings. This is not a common design for most terrestrial airplanes, although the design has been explored for high-altitude, long-endurance aircraft and powered sailplanes. Even for these aircraft, structural design of the wings can become an issue. At these low speeds and moderate values of cruise $C_{L}$ (between 1.0 and 1.5), wing loading would be low. For the case of the $300 \mathrm{~kg}$ (406.2 N on Titan) Titan aircraft, with a span of $10.5 \mathrm{~m}$ and an aspect ratio of 25, the wing loading of the Titan airplane $(W / S)$ would be approximately $92.1 \mathrm{~N} / \mathrm{m}^{2}$. That value is comparable to some advanced high-altitude, long-endurance craft, such as the Voyager ${ }^{20}$ (wing area of $33.70 \mathrm{~m}^{2}$ and a maximum takeoff weight on Earth of $43164 \mathrm{~N}$ ) which has a wing loading of approximately 1280 $\mathrm{N} / \mathrm{m}^{2}$ on Earth. Interestingly, if Voyager were brought directly to Titan, its wing loading would be $177 \mathrm{~N} / \mathrm{m}^{2}$. The major concern, though, would not be the low wing loading, but rather the challenge of building a structure that perhaps appears like Voyager, but must survive the high load cases created by its launch from Earth and entry into Titan while folded within the aeroshell. With that in mind, the desire for higher wing loading (affects velocity and structure) must be weighed against higher aspect ratios (to achieve higher L/D) and the aeroshell constraints (limits max span and wing area) given the power available. This trade study was not fully explored in this paper and future work should include doing so.

In summary, this design study has lead to the conclusion that the airship and airplane are both feasible craft for the exploration of Titan. However, with its landing and hovering capability, advantageous ability to float along with the wind to ease global coverage, and less unique (and complex) design, the airship is the preferred aerial vehicle for the exploration of Titan.

\section{Appendix}

Table A. TitanGRAM v1.0 Global Circulation Model Outputs

\begin{tabular}{|c|c|c|c|c|}
\hline $\begin{array}{c}\text { Deploy Altitude } \\
(\mathrm{km})\end{array}$ & $\begin{array}{c}\text { Atm. Density } \\
\left(\mathrm{kg} / \mathrm{m}^{3}\right)\end{array}$ & $\begin{array}{c}\text { Atm. Temp } \\
(\mathrm{K})\end{array}$ & $\begin{array}{c}\text { Pressure } \\
\left(\mathrm{N} / \mathrm{m}^{2}\right)\end{array}$ & $\begin{array}{c}\text { EW Wind } \\
(\mathrm{m} / \mathrm{s})\end{array}$ \\
\hline 10.04 & 3.48 & 81.3 & 82820 & 12.0 \\
\hline 9.49 & 3.57 & 81.8 & 85390 & 11.5 \\
\hline 9.04 & 3.65 & 82.2 & 87570 & 11.1 \\
\hline 8.50 & 3.74 & 82.6 & 90230 & 10.6 \\
\hline 8.02 & 3.82 & 83.0 & 92700 & 10.1 \\
\hline 7.50 & 3.92 & 83.5 & 95400 & 9.6 \\
\hline 7.03 & 4.00 & 83.9 & 97920 & 9.2 \\
\hline 6.51 & 4.09 & 84.4 & 100700 & 8.7 \\
\hline 6.01 & 4.19 & 84.8 & 103500 & 8.2 \\
\hline 5.51 & 4.28 & 85.3 & 106400 & 7.7 \\
\hline 5.02 & 4.37 & 85.8 & 109300 & 7.2 \\
\hline 4.49 & 4.47 & 86.2 & 112400 & 6.6 \\
\hline 4.00 & 4.57 & 86.7 & 115400 & 6.1 \\
\hline 3.52 & 4.65 & 87.2 & 118400 & 5.6 \\
\hline 3.01 & 4.74 & 87.8 & 121600 & 5.0 \\
\hline 2.50 & 4.83 & 88.6 & 124900 & 4.4 \\
\hline
\end{tabular}




\begin{tabular}{|c|c|c|c|c|}
\hline $\begin{array}{c}\text { Deploy Altitude } \\
(\mathrm{km})\end{array}$ & $\begin{array}{c}\text { Atm. Density } \\
\left(\mathrm{kg} / \mathrm{m}^{3}\right)\end{array}$ & $\begin{array}{c}\text { Atm. Temp } \\
(\mathrm{K})\end{array}$ & $\begin{array}{c}\text { Pressure } \\
\left(\mathrm{N} / \mathrm{m}^{2}\right)\end{array}$ & $\begin{array}{c}\text { EW Wind } \\
(\mathrm{m} / \mathrm{s})\end{array}$ \\
\hline 2.03 & 4.90 & 89.3 & 128000 & 3.8 \\
\hline 1.49 & 4.99 & 90.1 & 131600 & 3.1 \\
\hline 1.00 & 5.07 & 90.8 & 135000 & 2.5 \\
\hline 0.50 & 5.16 & 91.4 & 138400 & 1.7 \\
\hline 0.00 & 5.26 & 92.1 & 141900 & 0.7 \\
\hline
\end{tabular}

Table B. CDS and ACS Subsystem Component Masses

\begin{tabular}{|l|c|c|c|c|c|}
\hline \multicolumn{1}{|c|}{ Element } & $\begin{array}{c}\text { No. } \\
\text { Units }\end{array}$ & $\begin{array}{c}\text { Unit CBE } \\
\text { Mass (kg) }\end{array}$ & $\begin{array}{c}\text { Total CBE } \\
\text { Mass (kg) }\end{array}$ & $\begin{array}{c}\text { Max. } \\
\text { Contingency }\end{array}$ & $\begin{array}{c}\text { Expected } \\
\text { Mass (kg) }\end{array}$ \\
\hline $\begin{array}{l}\text { Flight Processor; >200 MIPS, } \\
\text { RAD750, cPCI }\end{array}$ & 1 & 0.3 & 0.3 & $20 \%$ & 0.36 \\
\hline Digital I/O - CAPI Board & 1 & 0.3 & 0.3 & $20 \%$ & 0.36 \\
\hline $\begin{array}{l}\text { State of Health and Attitude } \\
\text { Control - SMACI }\end{array}$ & 1 & 0.3 & 0.3 & $20 \%$ & 0.36 \\
\hline Power Distribution - PDB & 2 & 0.3 & 0.6 & $20 \%$ & 0.72 \\
\hline Power Control - PCATI & 1 & 0.3 & 0.3 & $20 \%$ & 0.36 \\
\hline Mother Board & 1 & 0.4 & 0.4 & $20 \%$ & 0.48 \\
\hline $\begin{array}{l}\text { Power Converters (For Integrated } \\
\text { Avionics Unit) }\end{array}$ & 1 & 0.4 & 0.4 & $20 \%$ & 0.48 \\
\hline Chassis & 1 & 1.7 & 1.7 & $20 \%$ & 2.04 \\
\hline Total Integrated Avionics Unit -1 & 9 & & 4.3 & & 5.16 \\
\hline Total Integrated Avionics Unit - 2 & 9 & & 4.3 & & 5.16 \\
\hline Solid State Data Recorder & 1 & 1.6 & 1.6 & $30 \%$ & 2.08 \\
\hline Total CDS & 19 & & 10.2 & & 12.4 \\
\hline Sun Sensors & 2 & 0.45 & 0.9 & $5 \%$ & 0.945 \\
\hline IMU & 1 & 4.5 & 4.5 & $5 \%$ & 4.725 \\
\hline IMU-Spare & 1 & 4.5 & 4.5 & $5 \%$ & 4.725 \\
\hline Radar Altimeter & 1 & 4.4 & 4.4 & $40 \%$ & 6.16 \\
\hline Antennas for Radar Altimeter & 2 & 0.16 & 0.32 & $30 \%$ & 0.416 \\
\hline Absorber for Radar Altimeter & 1 & 0.38 & 0.38 & $30 \%$ & 0.494 \\
\hline $\begin{array}{l}\text { Air Data System with pressure } \\
\text { and temperature }\end{array}$ & 2 & 2.5 & 5 & $30 \%$ & 6.5 \\
\hline Total ACS & $\mathbf{1 0}$ & & $\mathbf{2 0}$ & & $\mathbf{2 3 . 9 6 5}$ \\
\hline
\end{tabular}

\section{Acknowledgments}

The authors would like to thank the entire Titan Explorer Study team, especially Jody Fisher for entry trajectory inputs and TitanGRAM information, Mary Kae Lockwood for aerocapture study and mission architecture input, Anne Costa for drawings and sketches, and Mark Guynn for unmanned air vehicle advisement.

\section{References}

${ }^{1}$ Levine, J. S., “The Photochemistry of the Paleoatmosphere,” Journal of Molecular Evolution, No. 18, 1982a, pp. $161-172$.

${ }^{2}$ Levine, J. S., Augustsson, T. R., and Natarajan, M., “The Prebiological Paleoatmosphere: Stability and Composition,” Origins of Life, No. 12, 1982b, pp. 245-259.

${ }^{3}$ Levine, J. S., (ed.), The Photochemistry of the Early Atmsophere. The Photochemistry of Atmospheres: Earth, The Other Planets, and Comets, Academic Press, Inc., San Diego, CA, 1985, pp. 3-38.

${ }^{4}$ Yung, Y. L. and Demore, W. B., Photochemistry of Planetary Atmospheres, Oxford University Press, New York, 1999 
${ }^{5}$ McKay, C. P., Lorenz, R. L., and Lunine, J. I., “Analytic Solutions for the Antigreenhouse Effect: Titan and the Early Earth”. Icarus, No. 137, 1999, pp. 56-61.

${ }^{6}$ McKay, C. P., et. al., "Physical Properties of Organic Aerosols and Clouds on Titan,” Planetary and Space Science, No.49, 2001, pp. 79-99.

${ }^{7}$ Justus, C. G., Duvall, A. “Engineering-Level Model Atmospheres for Titan and Neptune,” AIAA-2003-4803, 39th AIAA/ASME/SAE/ASEE Joint Propulsion Conference and Exhibit, Huntsville, AL, July 20-23, 2003.

${ }^{8}$ Levine, J. S. Planetary Atmosphere, Encyclopedia of Physical Science and Technology, Third Edition, Vol 12, Academic Press, Inc., San Diego, CA. 2002, pp. 245-273.

${ }^{9}$ Lockwood, M.K., “Titan Aerocapture Systems Analysis”, AIAA-2003-4799, 39th AIAA/ASME/SAE/ASEE Joint Propulsion Conference and Exhibit, Huntsville, AL, July 20-23, 2003.

${ }^{10}$ Publication, “Nuclear Power in Space,” US Department of Energy, DOE-0071.

${ }^{11}$ Press Release, "Space Radioisotope Power Systems: Mulit-Mission Radioisotope Thermoelectric Generator, April 2002”, US Department of Energy, April 2002.

${ }^{12}$ Press Release, “Space Radioisotope Power Systems: Stirling Radioisotope Generator, April 2002”, US Department of Energy, April 2002.

${ }^{13}$ Lorenz, R.D., "Flight Power Scaling of Airplanes, Airships, and Helicopters: Application to Planetary Exploration," Journal of Aircraft, Vol. 28, No. 2, 2001, pp. 208-214.

${ }^{14}$ Prakash, R., Colby, L., Flaherty, K. W., Francis, S. R., Guduz, M. E., “Design of A Long Endurance Titan VTOL System,” AIAA Space 2005 Conference, (to be published).

${ }^{15}$ Gasbarre, J.F. and Dillman, R.A., "Preliminary Design and Analysis of the ARES Atmospheric Flight Vehicle Thermal Control System," SAE-2003-01-2686, 33rd International Conference on Environmental Systems (ICES), Vancouver, BC, July 710, 2003.

${ }^{16}$ Wright, H.S., Croom, M.A., Braun, R.D., Qualls, G.D., and Levine, J.S., “ARES Mission Overview - Capabilities and Requirements of the Robotic Aerial Platform," AIAA-2003-6577, 2nd AIAA "Unmanned Unlimited" Systems, Technologies, and Operations, San Diego, CA, September 15-18, 2003.

${ }^{17}$ Colozza, A.J., “Comparison of Mars Aircraft Propulsion Systems,” NASA CR-2003-212350.

${ }^{18}$ Khoury, G.A. and Gillett, J.D., (eds.), Airship Technology, Cambridge University Press, 1999.

${ }^{19}$ Hoerner, S.F., Fluid Dynamic Drag, (Published by author), New Jersey, 1957.

${ }^{20}$ Donald, David, (ed.), The Complete Encyclopedia of World Aircraft, Barnes \& Noble, New York, 1997, p. 792. 